\title{
Peripheral and central mechanisms of cough hypersensitivity
}

\author{
Nabita Singh ${ }^{1}$, Alexandria K. Driessen ${ }^{2}$, Alice E. McGovern ${ }^{2}$, Aung Aung Kywe Moe ${ }^{2}$, Michael J. Farrell ${ }^{1,3}$, \\ Stuart B. Mazzone ${ }^{2}$
}

${ }^{1}$ Department of Medical Imaging and Radiation Sciences, Monash University, Clayton, Australia; ${ }^{2}$ Department of Anatomy and Neuroscience, School of Biomedical Science, The University of Melbourne, Parkville, Australia; ${ }^{3}$ Monash Biomedical Imaging, Monash University, Clayton, Australia

Contributions: (I) Conception and design: SB Mazzone, MJ Farrell; (II) Administrative support: None; (III) Provision of study materials or patients: None; (IV) Collection and assembly of data: N Singh, AK Driessen, AAK Moe, AE McGovern; (V) Data analysis and interpretation: All authors; (VI) Manuscript writing: All authors; (VII) Final approval of manuscript: All authors.

Correspondence to: Stuart B. Mazzone, PhD. Department of Anatomy and Neuroscience, School of Biomedical Science, The University of Melbourne, Parkville, VIC 3010, Australia. Email: stuart.mazzone@unimelb.edu.au.

\begin{abstract}
Chronic cough is a difficult to treat symptom of many respiratory and some non-respiratory diseases, indicating that varied pathologies can underpin the development of chronic cough. However, clinically and experimentally it has been useful to collate these different pathological processes into the single unifying concept of cough hypersensitivity. Cough hypersensitivity syndrome is reflected by troublesome cough often precipitated by levels of stimuli that ordinarily don't cause cough in healthy people, and this appears to be a hallmark feature in many patients with chronic cough. Accordingly, a strong argument has emerged that changes in the excitability and/or normal regulation of the peripheral and central neural circuits responsible for cough are instrumental in establishing cough hypersensitivity and for causing excessive cough in disease. In this review, we explore the current peripheral and central neural mechanisms that are believed to be involved in altered cough sensitivity and present possible links to the mechanism of action of novel therapies that are currently undergoing clinical trials for chronic cough.
\end{abstract}

Keywords: Adenosine triphosphate; neurokinin receptor; sensitisation; vagal; descending inhibition; refractory cough

Submitted May 22, 2020. Accepted for publication Aug 20, 2020.

doi: $10.21037 /$ jtd-2020-icc-007

View this article at: http://dx.doi.org/10.21037/jtd-2020-icc-007

\section{Overview of cough and cough hypersensitivity syndrome}

Cough is an important physiological response to airway irritation but can become excessive and problematic in disease. The characteristic cough motor pattern is relatively simple, consisting of an initial inspiration, a brief expiration against a closed glottis and finally forced expiration with the glottis open $(1,2)$. This motor pattern generates large airflow velocities that effectively clear the airways of irritant material. Accordingly, cough plays an essential role in maintaining airway patency in both health and disease. However, despite the simplicity of an observable cough, the underlying neural mechanisms that lead to the production of a cough motor pattern can be quite complex. Firstly, cough can be initiated purely reflexively, mediated by the detection of irritant stimuli in the airway tree by vagal sensory nerve fibres leading to cough induction via the brainstem without any conscious control or regulation $(3,4)$. Additionally, cough can occur with varying levels of volitional or cognitive control. Indeed, cough can be initiated at will, with or without any sensory input from the airways, and it can also be effectively suppressed, both consciously and subconsciously, even at times of strong peripheral sensory drive $(5,6)$. This highlights some of the complexities in understanding the neural processes that control coughing, which is further complicated by multiple types of sensory neurons and receptors in the airways for detecting different 
cough stimuli and multiple levels of the central neural axis contributing to the integration of reflexive, affective and cognitive processes, all of which are capable of differentially regulating cough motor commands (7). It is therefore not surprising that our understanding of how cough becomes excessive and troublesome in disease is still rudimentary, which in turn translates to a lack of effective antitussives for relieving troublesome cough without disrupting the vital reflex needed for normal pulmonary health.

Chronic cough is defined as cough lasting longer than 8 weeks in the absence of any bacterial or viral infection $(8,9)$. It can be a difficult to treat symptom in respiratory medicine as it often fails to respond to common disease modifying therapies (chronic refractory cough) and can be present in patients without any identifiable associated disease (chronic unexplained cough) $(10,11)$. Patients with chronic cough often develop other physical and psychological co-morbidities, in part because troublesome cough can persist for many years (12). Such patients can cough many hundreds of times a day, severely impacting their personal relationships, capacity to work, social life and their overall quality of life (13). Regardless of the aetiology, chronic cough is now widely considered a syndrome (cough hypersensitivity syndrome) characterised by troublesome coughing to low level stimuli, consistent with an upregulation of activity in the neural circuits that ordinarily regulate coughing $(14,15)$. Neural hypersensitivity is argued to reflect the clinical observation that cough can be more easily triggered by tussive stimuli (hypertussivity) as well as by stimuli that would be considered innocuous in healthy people such as talking, laughing or eating (allotussivity) $(16,17)$. In addition, cough hypersensitive patients present with decreased stimulus thresholds for perceiving an airway irritation and a reduced capacity to suppress evoked cough in response to inhaled irritant stimuli in the laboratory $(18,19)$. This argues that changes in cough neural activity can occur at multiple locations within the neural circuits that ordinarily regulate coughing. In this brief review, we summarise the emerging literature describing the peripheral and central neural processes that likely contribute to cough hypersensitivity and relate this to the recent advances made in developing novel antitussive therapies.

\section{Neural mechanisms involved in cough}

\section{Peripheral cough sensors}

The airways and lungs are densely innervated by heterogenous populations of peripheral sensory fibres, most of which are vagal in origin and differentially respond to a range of chemical and mechanical stimuli (20). The vagal neurons originate from two anatomically and embryologically distinct collections of cells known as the jugular (superior) and nodose (inferior) vagal ganglia, situated bilaterally within the vagus nerves near the base of the skull $(20,21)$. Each neuron sends a peripheral axon that terminates within the larynx, bronchopulmonary airways or lung parenchyma, and a central axon that terminates in the brainstem, allowing for peripheral stimuli to be sensed and then relayed to central neural circuits that control respiratory physiology. The pattern of peripheral innervation by jugular and nodose neurons, and their physiology, differs and this is important with respect to cough. Jugular-derived sensory neurons are exclusively chemosensitive (mostly ' $\mathrm{C}$-fibre' axons responding to a wide range of chemical stimuli) and primarily terminate in the larynx, trachea and mainstem bronchi $(20,22)$. By contrast, most nodose-derived sensory neurons terminate in the intrapulmonary airways $(20,22)$, although a small number of specialised (A $\delta$-fibre) nodose neurons, highly sensitive to mechanical depression of the airway epithelium and surface liquid acidification, have terminations that are restricted to the larger airways $(4,23)$. Because cough is most readily induced from the larynx, trachea and large airways, by both chemical and mechanical stimuli, it is believed that both the jugular chemosensitive terminals and the specialised nodose 'cough receptor' terminals are wired centrally to encode for coughing.

The existence of two primary sensory neural pathways for cough allows for effective pulmonary defence against a wide range of physical and chemical irritants. For example, jugular cough-evoking chemoreceptor neurons often have terminals that interdigitate with epithelial cells and are exposed to the airway lumen $(20,23)$. These terminals respond to an array of chemical irritants, including exogenously inhaled chemicals and endogenously produced inflammatory mediators, which concentrate in the mucosa and lumen and as such this pathway is likely needed for defence against volatile agents entering the airways as well as cough accompanying airways inflammation in disease (20). A substantial body of evidence also points to this sensory pathway as playing a role in the perception of airway irritation, especially from the larynx $(13,24,25)$, suggestive of neural inputs from jugular neurons ascending the neuraxis to reach higher brain levels. By contrast, nodose cough receptors are largely not chemosensitive (with the exception of their sensitivity to acidification) (4). They also 
do not respond to airway stretch, which would ordinarily accompany breathing (4). Instead their position in the airway wall (23) and responsivity to epithelial 'touch' and rapid surface liquid acidification suggests that these neurons play an essential role in defending against aspiration, particulate matter inhalation and possibly excessive mucous accumulation. Consistent with this, cough evoked by this pathway is extremely rapid and often less subject to volitional control (26), perhaps typical of a hardwired neural brainstem circuit for defence against stimuli that could obstruct airflow with dire consequences.

\section{Central processing of cough}

Vagal sensory information from the airways and lungs is first processed in two termination sites in the brainstem: the nucleus of the solitary tract and the paratrigeminal nucleus (27). Anatomical tracing studies in rats and guinea pigs have shown that jugular and nodose ganglia differentially innervate these two regions. That is, the nodose sensory neurons terminate almost exclusively in the nucleus of the solitary tract, while jugular sensory neurons predominately terminate in the paratrigeminal nucleus $(28,29)$. Experiments in laboratory animals have confirmed that cough can be modulated by inhibiting sensory neuron inputs at either of these brainstem sites, dependent on the nature of the tussive stimulus (30-33). The nucleus of the solitary tract and paratrigeminal nucleus connect widely to medullary and pontine networks responsible for cardiorespiratory control and respiratory pattern generation via which automated motor responses, including cough, are encoded $(3,34,35)$. Recent studies using functional brain imaging during tussive challenges, for example with inhaled capsaicin, suggest that similar brainstem circuitry exists in humans, with capsaicin-evoked activations reported within regions encompassing the nucleus of the solitary tract, paratrigeminal nucleus, spinal trigeminal nuclei and cardiorespiratory processing regions equivalent to the ventrolateral medulla and midline raphe (36).

Cough stimuli can induce a perception of airway irritation (37). Sensory experiences associated with airway irritation (typically characterised as a burning, scratching or itching sensation) that drive the desire to cough are clinically referred to as the urge-to-cough (13). This argues for airway vagal sensory inputs ascending the brain, beyond the bulbar processing nuclei involved in automated responses. Consistent with this, circuit mapping experiments in rodents have revealed connections from brainstem vagal sensory processing nuclei to the higher brain that presumably convey this ascending input needed for perceptual encoding (27). Interestingly, differences exist in the organisation of the ascending pathways wired to neurons of the nodose and jugular ganglia, suggestive of important, yet unexplored, differences in the higherlevel processing attributes of these distinct airway sensory pathways (28). In human brain imaging experiments, the experience of an urge-to-cough is accompanied by neural activity in a widely distributed brain network encompassing brainstem activations described above as well as activity in the somatosensory cortices, insula cortex, midcingulate cortex, orbitofrontal cortex, supplementary motor area and cerebellum (38). Furthermore, this network has also been deconstructed using fMRI to map the neural correlates of regions encoding distinct sensorimotor processing aspects of the urge-to-cough perception of stimulus location and intensity (39). Brain regions that play a role in spatial discrimination include the prefrontal and posterior parietal cortices, while stimulus intensity is encoded by the sensorimotor and anterior insula cortices $(38,39)$.

Higher brain processes can also exert control over cough induction. Two independent fMRI studies have examined the supramedullary control of voluntary coughing in healthy participants $(40,41)$. Both studies showed that the voluntary induction of cough activates widespread brain regions that occur in the sensorimotor cortex, supplementary motor area, orbitofrontal cortex, insula cortex, mid-cingulate cortex, ventral and mediodorsal thalamus, caudate, putamen and cerebellum $(40,41)$. Notably, while cough induced with an accompanying airway stimulus is associated with some level of medullary activation, descending corticospinal rather than corticobulbar pathways have been suggested to regulate purely voluntary cough in which no ascending sensory inputs are present $(7,40)$. However, fMRI studies have only used whole brain imaging approaches to examine voluntary coughing and therefore it is necessary that fMRI optimised for brainstem imaging, which would increase spatial resolution, is employed to assess if medullary activation, expected for such changes in the respiratory pattern, occurs. Additionally, two cough suppression networks have been identified in humans using functional brain imaging. The first can be recruited by placebo cough suppression paradigms and shares organisational overlap with the well described descending analgesia system that modulate pain perception (i.e., conditioned pain modulation), including a strong dependence on the activation of the dorsolateral prefrontal cortex needed 
for cognitive modulation of sensory processing $(42,43)$. The second cough suppression network can be recruited voluntarily, and shares overlap with another commonly described motor suppression network in the brain required for response inhibition $(18,40,44)$. The associated brain regions that are activated include the anterior insula, supplementary motor area, motor cingulate cortex and right inferior frontal gyrus (40). This is in line with evidence showing activation of these regions during volitional breath holding and response inhibition of non-respiratory motor and non-motor tasks $(44,45)$.

\section{Neural mechanisms of cough hypersensitivity}

The description of the neural networks and processes governing airway sensory processing and cough above provides a framework to help understand how cough can become sensitised or upregulated in disease. The clinical phenotype of patients with cough hypersensitivity is increased cough frequency and enhanced cough sensitivity, which suggests that changes in two fundamental neural processes may be at play. Firstly, both increased cough sensitivity and enhanced cough frequency could reflect an increase in the activation or activation sensitivity of the vagal primary sensory neurons mediating cough. Alternatively, changes in cough and cough sensitivity could equally occur with altered neural processing in the brainstem or brain so as to alter the efficacy or 'gain' of the incoming sensory inputs. The latter could include processes that directly amplify incoming sensory inputs by making sensory integration sites more responsive to sensory inputs but could equally also include processes that reduce descending suppression network activity that ordinarily controls cough. Although the precise mechanisms that lead to these putative peripheral and central changes are unclear, support for both mechanisms are evident in the literature.

\section{Peripheral mediators of cough hypersensitivity}

The concept of peripheral sensitisation has been proposed to help explain the putative change in sensitivity of the airways to inhaled tussive stimuli. Peripheral sensitisation is well known to mediate other types of sensory hypersensitivity and encompasses inflammatory processes that alter primary sensory function (activity and excitability) and can additionally lead to molecular and structural plasticity in the primary sensory neurons themselves $(46,47)$. The putative mechanisms involved depend on the peripheral release of many different inflammatory mediators, including protons, pro-inflammatory cytokines, neurotrophic factors and adenosine triphosphate (ATP), each of which can activate cognate receptors on vagal cough sensory nerve fibres (48-52). A variety of cell types are potentially involved in the inflammatory response, depending on the nature of the underlying pathology, including epithelial and smooth muscle cells, resident and infiltrating immune cells (mast cells, macrophages and eosinophils), and perhaps neuronal support cells (glia) and the neurons themselves (49,51,53-56).

Empirical evidence in support of peripheral sensitisation occurring in the inflamed airways is largely derived from animal studies, although the clinical presentation of many patients with chronic cough is supportive of similar processes in humans. In laboratory animals, allergic and viral induced inflammation leads to upregulation of Transient Receptor Potential Vanilloid 1 (TRPV1) and the induction of neuropeptides in nodose-derived mechanoreceptors (including those that can evoke cough), changing their excitability and responsivity to be more akin to a chemoreceptor sensory neuron (51,57-59). Indeed, bacterial inflammation in the lungs (evoked by lipopolysaccharide exposure) induces wide-spread gene changes in vagal ganglia (60), suggestive of an inflammatory signalling axis between the airways and nervous system. Consistent with this, vagal airway sensory neurons express receptors for a wide variety of prostanoids, chemokines, cytokines and other inflammatory mediators including receptors for PGE2, PGD2, interferons, TNF $\alpha$ and ATP (21,49,61-65) that are known to be elevated in the human airways during inflammation (52,66-71). When activated these receptors lead to sensory neuron action potential firing and/or a reduction in the threshold needed to activate the nerve terminals by other stimuli of neuronal activity (21,49,61-65). Importantly, this signalling axis may be bidirectional, as the release of neuropeptides by airway sensory nerves has been implicated in promoting inflammatory cell influx and activation (72,73). In models of inflammatory lung disease, targeting receptors of inflammatory mediators reduces cough hypersensitivity as does targeting TRP channels and other receptors that regulate sensory nerve activation (48,74-79). Although direct measurements of sensory nerve activity in humans are difficult, inhalation of inflammatory mediators, such as PGF2- $\alpha$ and PGE2, effectively sensitises capsaicin-evoked cough in healthy participants $(80,81)$ and patients with chronic cough have altered nerve fibre profiles and elevated neuropeptides in the lung, consistent with neuronal plasticity (82-84). The preclinical animal 
data provided a rationale for pursuing clinical trials with compounds targeting peripheral nerve terminals and/or the neuroinflammatory molecules such as substance $\mathrm{P}$ in cough. Antagonists for TRP $(85,86)$ and neuronal sodium channels (87), thought to be important for neuronal activation, have so far performed poorly in clinical trials, as have peripherally acting antagonists for the neuropeptide, neurokinin 1 (NK1), receptor $(10,88)$.

\section{An increasing focus on ATP}

More promising clinical results have been obtained by targeting ATP mediated sensory nerve activation. ATP, and the metabolites adenosine diphosphate (ADP) and adenosine that are hydrolysed from ATP by ectonucleotidases, are essential mediators of many biological processes via purinergic receptors (89). P2X2 and $\mathrm{P} 2 \mathrm{X} 3$ receptors are of particular interest with respect to the vagal sensory nerves mediating cough, as ATP has been shown to induce action potential firing via heteromeric $\mathrm{P} 2 \mathrm{X} 2 / 3$ and weaker depolarizing currents via homomeric $\mathrm{P} 2 \mathrm{X} 3$ receptors $(21,64)$. While $\mathrm{P} 2 \mathrm{X} 3$ subunits are rather ubiquitously expressed by both nodose and jugular derived airway sensory neurons, the $\mathrm{P} 2 \mathrm{X} 2$ receptor subunit is restricted to the nodose ganglia $(21,64)$. Consequently, ATP can directly activate nodose neurons but probably can only modulate the activity of jugular neurons. This is of interest as $\mathrm{P} 2 \mathrm{X} 3$ selective antagonists are rapidly advancing through clinical trials as a novel treatment for chronic refractory cough. Leading this field is Gefapixant (also known as AF219 or MK-7624), a reversible allosteric antagonist of human P2X3 receptors and to a lesser extent P2X2/P2X3 receptors, currently in Phase 3 clinical trials (90). Phase $2 \mathrm{~b}$ results showed dose dependent reductions in awake cough frequency after 12 weeks of treatment compared to placebo, with a significant reduction in cough $(-37 \%)$ with $50 \mathrm{mg}$ of orally administered Gefapixant dosed twice daily (91). However, these effects were observed in the presence of a dose dependent increase in the adverse effect of dysgeusia (or taste distortions) (91). These taste effects are likely a result of inhibition of the $\mathrm{P} 2 \mathrm{X} 2 / 3$ receptor which is essential on lingual sensory neurons for transducing taste (92). Other compounds entering or in phase 2 clinical trials, including BLU-593 [Bellus Health (93)], S-600918 [Shionogi (94)], Bay 1817080 and BAY 1902607 [Bayer (95)], are reportedly more selective for $\mathrm{P} 2 \mathrm{X} 3$ and have limited effects on taste. Whether these compounds retain antitussive properties awaits the formal release of clinical trial data.
Patients with conditions related to chronic cough, such as chronic obstructive pulmonary disease (COPD) and asthma, have increased concentrations of ATP in their breath condensate $(70,71)$ and chronic refractory cough patients are more sensitive than healthy controls to inhaled ATP as a tussive stimulus (96-98). However, it remains unclear if increased extracellular ATP acts as a neural activator or sensitiser to upregulate cough. While airway sensory neurons expressing the $\mathrm{P} 2 \mathrm{X} 2 / \mathrm{P} 2 \mathrm{X} 3$ heteromeric receptor can be activated by ATP $(21,64)$, ATP inhalation is a relatively weak tussive stimulus in healthy guinea pigs and humans (30,96-99). This may in part be because the primary cough evoking vagal sensory fibres, the nodose $\mathrm{A} \delta$ cough receptors and jugular C-fibre chemoreceptors, do not induce action potential firing in response to ATP (4). This would cast doubt as to whether increased extracellular ATP alone is sufficient to directly stimulate cough evoking sensory neurons.

Alternately, increased ATP may sensitise airway sensory nerves, rendering them more excitable to concomitant activation by other stimuli. In this regard, ATP has been shown to effectively potentiate citric acid evoked cough in animal studies (99). Intriguingly, this sensitising capacity appears not to be generic for all stimuli, as capsaicin evoked cough in animals and humans is unaffected by ATP (99). While protons can evoke cough via both nodose cough receptors and jugular chemoreceptors (100), capsaicin cough appears to be selectively mediated by jugular chemoreceptors (101). If our understanding of the role of nodose and jugular neurons in cough is correct, then these data may highlight an importance of nodose neurons involved in the sensitising effect of ATP. However, these data may equally suggest a unique relationship between purine and proton signalling in sensory neurons, and this could be of significance clinically as both ATP and protons are increased in inflammatory respiratory diseases $(48,102)$. Consistent with this, a recent study assessing ATP and proton interactions in somatosensory neurons of the dorsal root ganglia confirms a functional interaction between the Acid Sensing Ion Channel 3 (ASIC3) and the $\mathrm{P} 2 \mathrm{X} 3$ receptor, forming a cognate receptor that effectively enhances pain signalling (103). We have noted that adjusting the $\mathrm{pH}$ of ATP challenge solutions, from neutral to acidic, dramatically increases evoked cough in guinea pigs across a range of ATP challenge doses (Figure 1). Furthermore, analysis of our recent single cell transcriptomic profiling data, of airway projecting vagal sensory neurons in the mouse (104), suggests that the genes 

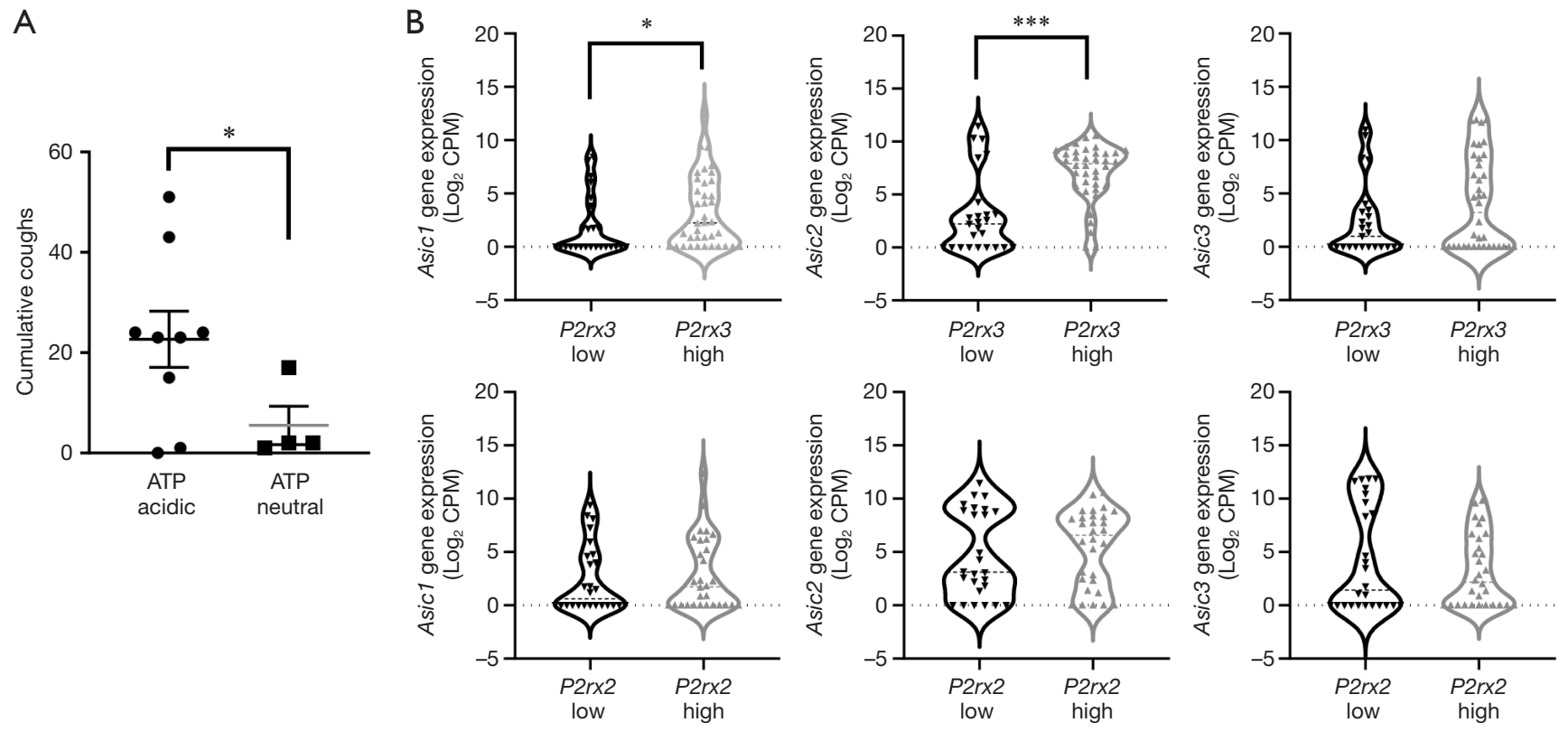

Figure 1 Gene expression and cough data in rodents that suggest the potential for synergistic purinergic and acid signalling in the airways. (A) Using whole body plethysmography, conscious freely moving adult guinea pigs were exposed to $2 \mathrm{mM}, 20 \mathrm{mM}$ and $200 \mathrm{mM}$ of adenosine 5 '-triphophaste at neutral or acidic $(\leq 5) \mathrm{pH}$. ATP was nebulized to the guinea pigs for 5-minutes, followed by a 10-minute response period. Each dose was separated by a one-minute period to allow respiratory parameters to return to baseline. The cumulative total coughs across doses were compared between the ATP acidic and ATP neutral conditions. * $\mathrm{P}<0.05$. (B) Violin plots assessing enrichment of Acid Sensing Ion Channel (Asic) mRNA in neurons with low or high expression of the purinergic receptor genes, $P 2 r \times 2$ and $P 2 r \times 3$. These analyses show that Asic1 and Asic2 are significantly (*, $\mathrm{P}<0.05$ and $\left.{ }^{* * *}, \mathrm{P}<0.01\right)$ enriched in $P 2 r x 3$ high expressing neurons, whereas none of the Asic genes were enriched in the $P 2 r \times 2$ high expressing neurons. RNA-seq data from murine airway specific vagal ganglia sensory neurons was obtained from (Mazzone et al., 2020). Asic4 was not detected in any cells analysed.

for multiple ASICs are specifically enriched in neurons that express high levels of $\mathrm{P} 2 \mathrm{X} 3$, but not $\mathrm{P} 2 \mathrm{X} 2$, receptor mRNA (Figure 1). These are suggestive data but argue that additional work is warranted in this area. Indeed, if this potentiating effect of ATP on the cough response to acid aerosol inhalation is also present in humans, it could bring a new insight into the mechanism underlying the therapeutic efficacy of selective $\mathrm{P} 2 \mathrm{X} 3$ antagonist in chronic refractory cough and suggest that more effective antitussives could result from targeting both purine and acid signalling in vagal sensory neurons.

Modulating ATP activity at vagal sensory neurons may also be achieved via targeting mechanisms involved in ATP release in the airways. At present, the cells that release ATP in chronic cough is not known, but epithelial cells are a primary candidate. Three cellular mechanisms for mediating ATP release have dominated the cough field and they are the hemichannel Pannexin 1, P2X7 receptor and TRPV4 and their associated interactions (105-108).
However, recent studies have revealed that Pannexin 1 and $\mathrm{P} 2 \mathrm{X} 7$ receptors are not essential for ATP release and signalling (109-111). Furthermore, the failure of a TRPV4 antagonist (GSK2798745) to reduce cough in a recent clinical trial (112) also argues against any substantive role of TRPV4. Other avenues for modulating extracellular ATP concentrations have not been explored, but could include targeting ectonucleotidases that metabolize extracellular ATP (54), the vesicular nucleotide transporter (VNUT) shown to be the principle component for packaging ATP into secretory vesicles (113) and the more recently identified calcium homeostasis modulator 1 and 3 (CAHLM1 and 3), which are non-selective weakly voltage gated calcium permeable ion channels important for ATP release in taste cells (114-116).

\section{Central mediators of cough hypersensitivity}

Central sensitisation is a process characterised by changes 
in excitability of central neural pathways involved in processing sensory inputs from the periphery $(46,47)$. Enhanced central nervous system (CNS) processing may involve neuroinflammatory mechanisms that activate glial cells, the primary cells regulating inflammatory states in the brain $(117,118)$. This includes the activation of microglia and astrocytes which release mediators capable of sensitising CNS neurons and evoking molecular and structural plasticity in neurons $(117,119-121)$, similar to that described above for the peripheral nervous system during inflammation. We have previously reviewed these processes in detail along with the experimental evidence for central sensitisation contributing to excessive cough in disease (122). Essentially, behavioural and regional brain signal changes during tussive challenges in patients show a common pattern, whereby the relationship between stimulus and response is shifted toward heightened sensitivity relative to outcomes from healthy people (Figure 2). Here we will restrict our discussion to two observations which support the notion that CNS circuits are functionally altered in humans with chronic cough.

Patients with chronic refractory cough demonstrate a heightened sensitivity to inhalation of the cough evoking compound capsaicin $(18,123)$. Using functional brain imaging, we previously investigated brain responses to capsaicin inhalation in cough hypersensitivity patients. This approach involves the measurement of blood oxygen level dependent (BOLD) signals which are an indicator of neural activity. Localised increases in cerebral blood flow is associated with increases in neural activity and fMRI measures of this response are used to infer neural responses. Using these measures cough hypersensitivity patients show increased neural activity in areas of the brainstem that may in turn contribute to a heightened sensitivity to cough stimuli (18). In particular, the midbrain cuneiformis nucleus, midbrain raphe nuclei and the periaqueductal gray all showed increased neural activity during cough challenge compared to healthy controls (18). In fact, increased sensitivity to capsaicin was strongly correlated with lateral midbrain regional activations, suggesting an upregulation of urge-to-cough neural circuits in chronic cough hypersensitivity (18). This was an interesting observation, as in conditions of chronic pain $(124,125)$ where central sensitisation is known to occur, an upregulation of activity in similar midbrain regions has been reported to accompany the heighted perception of noxious stimuli. However, at present, the mechanisms leading to this heightened midbrain activity in cough patients remain unclear.
Our brain imaging studies of cough patients also revealed an alternative mechanism for heightened cough sensitivity. Cough hypersensitive participants show reduced levels of activation in the central network that is enlisted during voluntary cough suppression during tussive challenges with capsaicin (18). This included diminished activity in the dorsomedial prefrontal cortex, anterior mid cingulate cortex and inferior frontal gyrus (18). Intriguingly, the cough hypersensitive patients with the highest levels of uncontrolled coughing during capsaicin challenge tests also showed the largest reductions in cough suppression network activity (18). A recent clinical study directly investigating cough suppression capacity in chronic refractory cough patients showed that heightened capsaicin cough sensitivity was accompanied by a reduced capacity to voluntarily suppress evoked coughing (126). In an alternate cohort of cigarette smokers who instead experienced decreased sensitivity to cough evoking stimuli (i.e., higher threshold to elicit the urge-to-cough and cough), an opposite central neural phenotype was observed in that they responded to capsaicin challenge with increased activity in descending inhibitory network activity (127). Together these data suggest that changes in the efficacy of central inhibitory systems may play a significant role in determining cough in response to airway irritant stimuli. A failure to recruit cough suppression brain regions provides a prospective explanation for increased cough frequency in cough hypersensitivity syndrome and might provide a mechanism by which speech therapy helps to relieve excessive cough (i.e., by improving central control) $(128,129)$. This general hypothesis is supported by the reported reduction in descending inhibitory control that occurs in pain hypersensitivity $(130,131)$.

Therapeutically targeting the putative CNS contributions to chronic cough may offer alternative approaches for cough control, although suitable central pharmacological targets are not fully defined. While opioids are key mediators of descending inhibition in pain (132) and morphine is useful clinically to treat cough, alternative approaches are warranted given the side-effects and dependency that accompany opioid use (10). Several putative centrally acting compounds (the central glutamate receptor antagonist Memantine and the central acetylcholine receptor agonist Bradanicline) failed to demonstrate cough suppression in recent clinical trials. Clinical trial data assessing the highly CNS penetrant NK1 receptor antagonist, Orvepitant, in chronic refractory cough patients is more encouraging. The results from Phase II trials suggests 


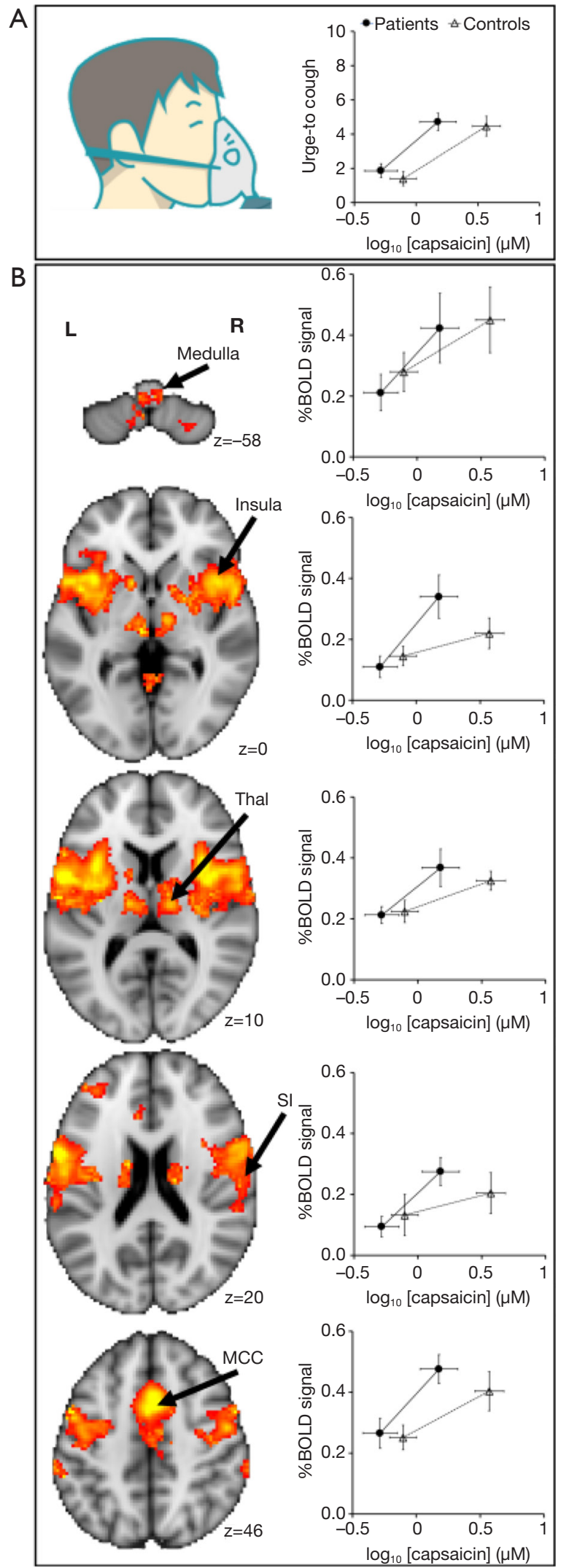

Figure 2 Behavioural and regional brain activation responses to tussive challenges in healthy participants and patients with cough hypersensitivity syndrome. Participants inhaled two concentrations of nebulised capsaicin solution while they were undergoing fMRI scans. These concentrations were the maximum suppressible dose and a lower level of capsaicin. These stimuli were associated with reports of an urge-to-cough sensation and participants were instructed to suppress coughing during the scanning. Responses were confined to the sensory experience of urge-tocough and associated efforts to suppress cough. (A) Patients with cough hypersensitivity show increased levels of urge-to-cough in response to capsaicin inhalation, represented by a leftward shift in the stimulus/response function compared to values from healthy people. (B) Blood oxygen level dependent (BOLD) signal changes associated with inhalation of capsaicin at two concentrations also show increased levels of response among cough patients compared to controls. This evidence of sensitisation can be seen throughout the distributed brain regions that respond during capsaicin inhalation, and include the medulla, insula, thalamus (Thal), primary somatosensory cortex (SI), and midcingulate cortex (MCC). These sensitised responses could be related to a number of functional processes including the representation of the urge to cough sensation and active efforts to suppress coughing. This protocol does not provide any insights into activation associated with coughing. Left side of brain is on left side of image. Location of axial slices is at " $\mathrm{z}$ " mm distance below (-ve) or above (+ve) the anterior commissure in the Montreal Neurosciences Institute brain space. 


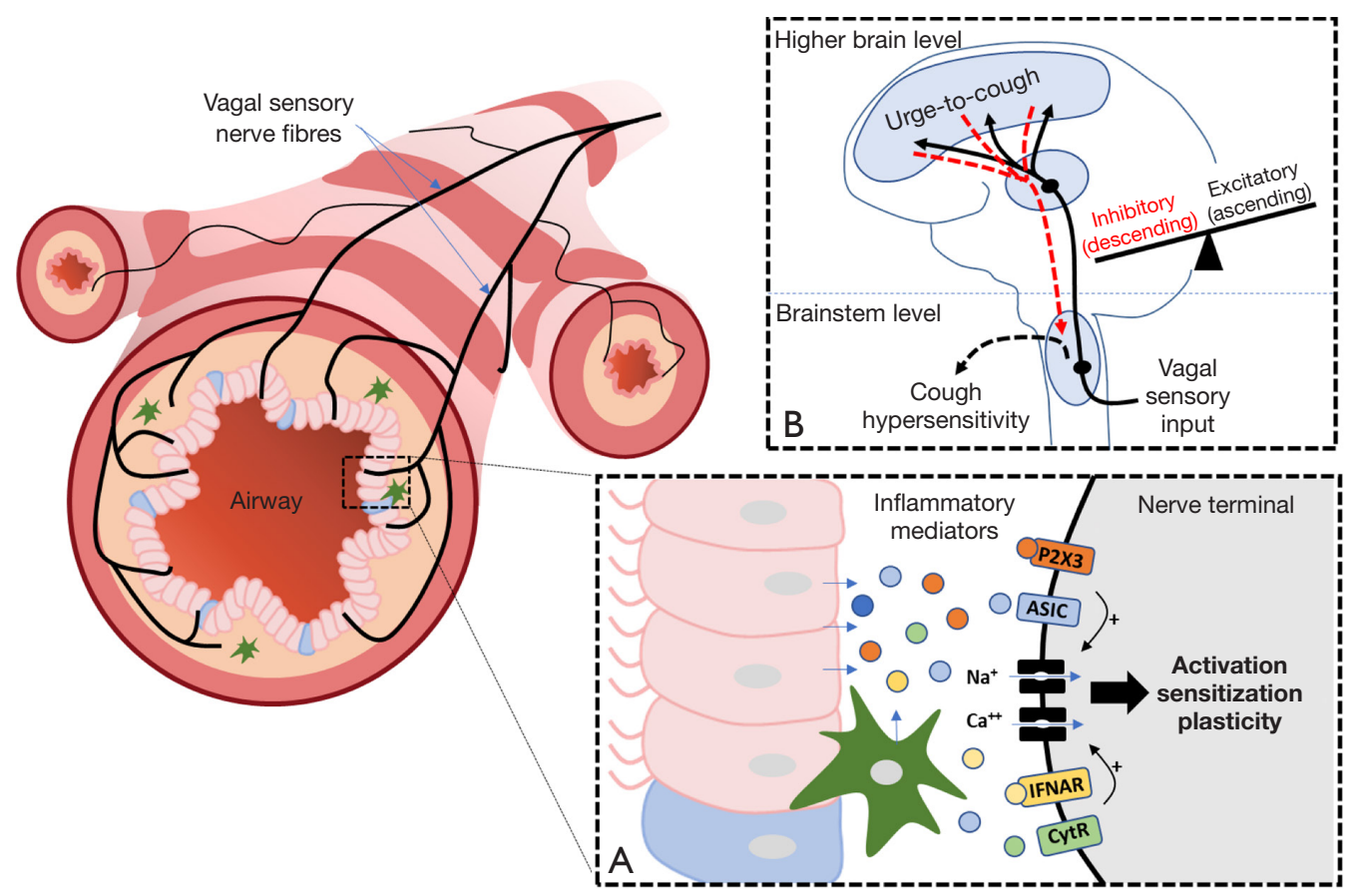

Figure 3 Stylised cartoon summarising putative peripheral and central processes leading to cough hypersensitivity. The airways are innervated by differing subsets of vagal sensory nerve fibres, some of which evoke coughing when activated. (A) It is hypothesised that patients with chronic cough have elevated levels of proinflammatory mediators, including ATP, protons, cytokines, interferons and others. These are likely released by airway structural cells and/or resident and infiltrating inflammatory cells. Vagal sensory nerve terminals within the airway mucosa express a range of receptors for these proinflammatory mediators and when activated open neuronal ion channels leading to altered sensory neuron activity and, over time, neural phenotype. Blocking sensory nerve activation by inflammatory mediators (namely with $\mathrm{P} 2 \mathrm{X} 3$ receptor antagonists) has proved promising in recent clinical trials but fails to completely suppress excessive coughing, suggesting multiple mechanisms may need to be targeted. Blocking sensory neuron ion channel activity has so far been disappointing in human cough trials. (B) Vagal sensory neurons input to the brainstem and connect into circuits that ascend to the higher brain. Reflex cough, the urge to cough and behavioural modulation of coughing can occur through these lower and higher order brain circuits, the latter involving descending pathways that modulate ascending inputs at various levels of the neural pathway. Evidence supports an imbalance of ascending excitatory activity and reduced descending inhibitory activity in brain networks controlling cough in patients with cough hypersensitivity. Restoring this balance with drugs that target sensory processing (e.g., NK1 receptor antagonists) or descending control (e.g., GABA and nicotinic acetylcholine receptor agonists) have been recently trialled with mixed success. See text for further details. Abbreviations: ASIC, Acid Sensing Ion Channels; CytR, unspecified cytokine receptors, IFNAR, interferon receptors; P2X3, sensory neuron specific purinergic (ATP) receptor.

that Orvepitant has some efficacy for cough reduction, perhaps limited to a subset of patients, but interestingly has more pronounced and significant improvements to cough patient reported quality of life measures (133). This could argue a mechanism of action within cognitive brain areas involved in processing airway sensory inputs and is suggestive that heightened cough frequency and the altered affective dimension of excessive cough may involve different mechanisms. Much more work is needed in this space to resolve these interesting possibilities.

\section{Conclusions}

Cough is a troublesome symptom for patients and a challenge to treat for clinicians. Restoring normal cough sensitivity and reducing excessive cough is preferred over complete cough suppression, given the important role cough plays in normal pulmonary health. Evidence supports a role for both peripheral and central changes in cough neural pathways (Figure 3) and at present the most promising therapeutic targets for controlling cough are 
via modulation of purinergic signalling on vagal sensory neurons and central processing that perhaps involves NK1 receptors. However, as neither of these targets appear to completely resolve troublesome cough, more work is needed, and other opportunities exist for future discoveries to impact chronic cough.

\section{Acknowledgments}

Funding: This research was supported by grants to Dr. Mazzone and Dr. Farrell from the National Health \& Medical Research Council (NHMRC) of Australia (APP1042528).

\section{Footnote}

Provenance and Peer Review: This article was commissioned by the Guest Editor (Kefang Lai) for the series "3rd International Cough Conference" published in Fournal of Thoracic Disease. The article has undergone external peer review.

Conflicts of Interest: All authors have completed the ICMJE uniform disclosure form (available at http:// dx.doi.org/10.21037/jtd-2020-icc-007). The series "3rd International Cough Conference" was commissioned by the editorial office without any funding or sponsorship. Dr. SBM serves as an unpaid editorial board member of fournal of Thoracic Disease. Dr. SBM reports grants and personal fees from Merck, personal fees from NeRRe therapeutics, outside the submitted work. The authors have no other conflicts of interest to declare.

Ethical Statement: The authors are accountable for all aspects of the work in ensuring that questions related to the accuracy or integrity of any part of the work are appropriately investigated and resolved.

Open Access Statement: This is an Open Access article distributed in accordance with the Creative Commons Attribution-NonCommercial-NoDerivs 4.0 International License (CC BY-NC-ND 4.0), which permits the noncommercial replication and distribution of the article with the strict proviso that no changes or edits are made and the original work is properly cited (including links to both the formal publication through the relevant DOI and the license). See: https://creativecommons.org/licenses/by-ncnd/4.0/.

\section{References}

1. Fontana GA, Widdicombe J. What is cough and what should be measured? Pulm Pharmacol Ther 2007;20:307-12.

2. Korpas J, Widdicombe JG. Aspects of the cough reflex. Respir Med 1991;85:3-5.

3. Shannon R, Baekey DM, Morris KF, et al. Brainstem respiratory networks and cough. Pulm Pharmacol 1996;9:343-7.

4. Canning BJ, Mazzone SB, Meeker SN, et al. Identification of the tracheal and laryngeal afferent neurones mediating cough in anaesthetized guinea-pigs. J Physiol 2004;557:543-58.

5. Eccles R. Central mechanisms IV: conscious control of cough and the placebo effect. Handb Exp Pharmacol 2009;187:241-62.

6. Ando A, Farrell MJ, Mazzone SB. Cough-related neural processing in the brain: a roadmap for cough dysfunction? Neurosci Biobehav Rev 2014;47:457-68.

7. Mazzone SB, McGovern AE, Cole LJ, et al. Central nervous system control of cough: pharmacological implications. Curr Opin Pharmacol 2011;11:265-71.

8. Morice AH, Fontana GA, Sovijarvi ARA, et al. The diagnosis and management of chronic cough. Eur Respir J 2004;24:481-92.

9. Song WJ, Chung KF. Exploring the clinical relevance of cough hypersensitivity syndrome. Expert Rev Respir Med 2020;14:275-84.

10. Song WJ, Chung KF. Pharmacotherapeutic Options for Chronic Refractory Cough. Expert Opin Pharmacother 2020;21:1345-58.

11. Gibson P, Wang G, McGarvey L, et al. Treatment of unexplained chronic cough: CHEST guideline and expert panel report. Chest 2016;149:27-44.

12. Ovsyannikov ES, Avdeev SN, Budnevsky AV, et al. Influence of anxiety/depression on the subjective evaluation of cough in patients with Chronic Obstructive Pulmonary Disease and Obesity. Medicina (Kaunas) 2019;55:134.

13. Hilton E, Marsden P, Thurston A, et al. Clinical features of the urge-to-cough in patients with chronic cough. Respir Med 2015;109:701.

14. Dicpinigaitis PV, Enilari O, Cleven KL. Prevalence of Arnold nerve reflex in subjects with and without chronic cough: relevance to cough hypersensitivity syndrome. Pulm Pharmacol Ther 2019;54:22-4.

15. Chung KF. Chronic 'cough hypersensitivity syndrome': 
a more precise label for chronic cough. Pulm Pharmacol Ther 2011;24:267-71.

16. Morice AH, Millqvist E, Belvisi M, et al. Expert opinion on the cough hypersensitivity syndrome in respiratory medicine. Eur Respir J 2014;44:1132-48.

17. Chung KF, McGarvey L, Mazzone SB. Chronic cough as a neuropathic disorder. Lancet Respir Med 2013;1:414-22.

18. Ando A, Smallwood D, McMahon M, et al. Neural correlates of cough hypersensitivity in humans: evidence for central sensitisation and dysfunctional inhibitory control. Thorax 2016;71:323-9.

19. Farrell MJ, Mazzone SB. Are neural pathways processing airway inputs sensitised in patients with cough hypersensitivity? Pulm Pharmacol Ther 2019;57:101806.

20. Mazzone SB, Undem BJ. Vagal afferent innervation of the airways in health and disease. Physiol Rev 2016;96:975-1024.

21. Nassenstein C, Taylor-Clark TE, Myers AC, et al. Phenotypic distinctions between neural crest and placodal derived vagal C-fibres in mouse lungs. J Physiol 2010;588:4769-83.

22. McGovern AE, Davis-Poynter N, Yang SK, et al. Evidence for multiple sensory circuits in the brain arising from the respiratory system: an anterograde viral tract tracing study in rodents. Brain Struct Funct 2015;220:3683-99.

23. Mazzone SB, Reynolds SM, Mori N, et al. Selective expression of a sodium pump isozyme by cough receptors and evidence for its essential role in regulating cough. J Neurosci 2009;29:13662-71.

24. Vertigan AE, Kapela SM, Kearney EK, et al. Laryngeal dysfunction in cough hypersensitivity syndrome: a crosssectional observational study. J Allergy Clin Immunol Pract 2018;6:2087-95.

25. Vertigan AE, Kapela SL, Gibson PG. Chronic cough in vocal cord dysfunction: description of a clinical entity. Respir Med 2020;168:105990.

26. Mazzone SB. An overview of the sensory receptors regulating cough. Cough 2005;1:2.

27. McGovern AE, Davis-Poynter N, Farrell MJ, et al. Transneuronal tracing of airways-related sensory circuitry using herpes simplex virus 1 , strain H129. Neuroscience 2012;207:148-66.

28. McGovern AE, Driessen AK, Simmons DG, et al. Distinct brainstem and forebrain circuits receiving tracheal sensory neuron inputs revealed using a novel conditional anterograde transsynaptic viral tracing system. J Neurosci 2015;35:7041-55.

29. Driessen AK, Farrell MJ, Mazzone SB, et al. The role of the paratrigeminal nucleus in vagal afferent evoked respiratory reflexes: a neuroanatomical and functional study in guinea pigs. Front Physiol 2015;6:378.

30. Driessen AK, McGovern AE, Behrens R, et al. A role for neurokinin 1 receptor expressing neurons in the paratrigeminal nucleus in bradykinin-evoked cough in guinea-pigs. J Physiol 2020;598:2257-75.

31. Mutolo D, Bongianni F, Cinelli E, et al. Modulation of the cough reflex by antitussive agents within the caudal aspect of the nucleus tractus solitarii in the rabbit. Am J Physiol Regul Integr Comp Physiol 2008;295:R243-251.

32. Cinelli E, Iovino L, Bongianni F, et al. GABAA- and glycine-mediated inhibitory modulation of the cough reflex in the caudal nucleus tractus solitarii of the rabbit. Am J Physiol Lung Cell Mol Physiol 2016;311:L570-L580.

33. Poliacek I, Pitts T, Rose MJ, et al. Microinjection of kynurenic acid in the rostral nucleus of the tractus solitarius disrupts spatiotemporal aspects of mechanically induced tracheobronchial cough. J Neurophysiol 2017;117:2179-87.

34. Jakus J, Poliacek I, Halasova E, et al. Brainstem circuitry of tracheal-bronchial cough: c-fos study in anaesthetized cats. Respir Physiol Neurobiol 2008;160:289-300.

35. Gestreau C, Bianchi AL, Grélot L. Differential brainstem Fos-like immunoreactivity after laryngeal-induced coughing and its reduction by codeine. J Neurosci 1997;17:9340-52.

36. Bautista TG, Leech J, Mazzone SB, et al. Regional brainstem activations during capsaicin inhalation using functional magnetic resonance imaging in humans. J Neurophysiol 2019;121:1171-82.

37. Davenport PW. Clinical cough I: the urge-tocough: a respiratory sensation. Handb Exp Pharmacol 2009;187:263-76.

38. Mazzone SB, McLennan L, McGovern AE, et al. Representation of Capsaicin-evoked urge-to-cough in the Human Brain using Functional Magnetic Resonance Imaging. Am J Resp Crit Care Med 2007;176:327-32 .

39. Farrell MJ, Cole LJ, Chiapoco D, et al. Neural correlates coding stimulus level and perception of capsaicin-evoked urge-to-cough in humans. Neuroimage 2012;61:1324-35.

40. Mazzone SB, Cole LJ, Ando A, et al. Investigation of the neural control of cough and cough suppression in humans using Functional Brain Imaging. J Neurosci 2011;31:2948-58.

41. Simonyan K, Saad ZS, Loucks TM, et al. Functional neuroanatomy of human voluntary cough and sniff 
production. Neuroimage 2007;37:401-9.

42. Leech J, Mazzone SB, Farrell MJ. The effect of placebo conditioning on capsaicin-evoked urge to cough. Chest 2012;142:951-7.

43. Youssef AM, Macefield VG, Henderson LA. Cortical influences on brainstem circuitry responsible for conditioned pain modulation in humans. Hum Brain Mapp 2016;37:2630-44.

44. Duann JR, Ide JS, Luo X, et al. Functional connectivity delineates distinct roles of the inferior frontal cortex and presupplementary motor area in stop signal inhibition. J Neurosci 2009;29:10171-9.

45. Cai W, Cannistraci CJ, Gore JC, et al. Sensorimotorindependent prefrontal activity during response inhibition. Hum Brain Mapp 2014;35:2119-36.

46. Pak DJ, Yong RJ, Kaye AD, et al. Chronification of pain: mechanisms, current understanding, and clinical implications. Curr Pain Headache Rep 2018;22:9.

47. Meacham K, Shepherd A, Mohapatra DP, et al. Neuropathic pain: central vs. peripheral mechanisms. Curr Pain Headache Rep 2017;21:28.

48. Audrit KJ, Delventhal L, Aydin Ö, et al. The nervous system of airways and its remodelling in inflammatory lung disease. Cell Tissue Res 2017;367:571-90.

49. Deng Z, Zhou W, Sun J, et al. IFN- enhances the cough reflex sensitivity via calcium influx in vagal sensory neurons. Am J Respir Crit Care Med 2018;198:868-79.

50. Clarke R, Monaghan K, About I, et al. TRPA1 activation in a human sensory neuronal model: relevance to cough hypersensitivity? Eur Respir J 2017;50:1-10.

51. Undem BJ, Hunter DD, Liu M, et al. Allergen-induced sensory neuroplasticity in airways. Int Arch Allergy Immunol 1999;118:150-3.

52. Birring SS, Parker D, Brightling CE, et al. Induced sputum inflammatory mediator concentrations in chronic cough. Am J Respir Crit Care Med 2004;169:15-9.

53. McGovern AE, Mazzone SB. Neural regulation of inflammation in the airways and lungs. Auton Neurosci 2014;182:95-101.

54. Chávez J, Vargas MH, Martínez-Zúñiga J, et al. Allergic sensitization increases the amount of extracellular ATP hydrolyzed by guinea pig leukocytes. Purinergic Signal 2019;15:69-76.

55. Takahara N, Ito S, Furuya K, et al. Real-time imaging of ATP release induced by mechanical stretch in human airway smooth muscle cells. Am J Respir Cell Mol Biol 2014;51:772-82.

56. Srisomboon Y, Squillace DL, Maniak PJ, et al. Fungal allergen-induced IL-33 secretion involves cholesteroldependent, VDAC-1 mediated ATP release from the airway epithelium. J Physiol 2020;598:1829-45.

57. Dinh QT, Mingomataj E, Quarcoo D, et al. Allergic airway inflammation induces tachcykinin peptides expression in vagal sensory neurons innervating mouse airways. Clin Exp Allergy 2005;35:820-5.

58. Zhang G, Lin RL, Wiggers M, et al. Altered expression of TRPV1 and sensitivity to capsaicin in pulmonary myelinated afferents following chronic airway inflammation in the rat. J Physiol 2008;586:5771-86.

59. Undem BJ, Carr MJ, Kollarik M. Physiology and plasticity of putative cough fibres in the guinea pig. Pulm Pharmacol Ther 2002;15:193-8.

60. Kaelberer MM, Caceres AI, Jordt SE. Activation of a nerve injury transcriptional signature in airway-innervating sensory neurons after lipopolysaccharide-induced lung inflammation. Am J Physiol Lung Cell Mol Physiol 2020;318:L953-L964.

61. Lee LY, Kwong K, Lin YS, et al. Hypersensitivity of bronchopulmonary C-fibers induced by airway mucosal inflammation: cellular mechanisms. Pulm Pharmacol Ther 2002;15:199-204.

62. Maher SA, Birrell MA, Adcock JJ, et al. Prostaglandin $\mathrm{D} 2$ and the role of the DP1, DP2 and TP receptors in the control of airway reflex events. Eur Respir J 2015;45:1108-18.

63. Lin RL, Gu Q, Khosravi M, et al. Sustained sensitising effects of tumor necrosis factor alpha on sensory nerves in lung and airways. Pulm Pharmacol Ther 2017;47:29-37.

64. Kwong K, Kollarik M, Nassenstein C, et al. P2X2 receptors differentiate placodal vs. neural crest $\mathrm{C}$-fiber phenotypes innervating guinea pig lungs and esophagus. Am J Physiol Lung cell Mol Physiol 2008;295:L858-865.

65. Bonvini SJ, Birrell MA, Grace MS, et al. Transient receptor potential cation channel, subfamily $\mathrm{V}$, member 4 and airway afferent activation: role of adenosine triphosphate. J Allergy Clin Immunol 2016;138:249-261.e12.

66. Uchida Y, Soma T, Nakagome K, et al. Implication of prostaglandin D2 and leukotrienes in exhaled breath condensates of asthma. Ann Allergy Asthma Immunol 2019;123:81-88.e1.

67. Peebles RS Jr. Prostaglandins in asthma and allergic disease. Pharmacol Ther 2019;193:1-19.

68. Zhu Y, Song D, Song Y, et al. Interferon gamma induced inflammatory responses through the interaction of CEACAM1 and PI3K in airway epithelial cells. J Transl Med 2019;17:147. 
69. Jatakanon A, Lalloo UG, Lim S, et al. Increased neutrophils and cytokines, TNF-alpha and IL-8, in induced sputum of non-asthmatic patients with chronic dry cough. Thorax 1999;54:234-7.

70. Lázár Z, Huszár E, Kullmann T, et al. Adenosine triphosphate in exhaled breath condensate of healthy subjects and patients with chronic obstructive pulmonary disease. Inflamm Res 2008;57:367-73.

71. Lázár Z, Cervenak L, Orosz M, et al. Adenosine triphosphate concentration of exhaled breath condensate in asthma. Chest 2010;138:536-42.

72. Morelli AE, Sumpter TL, Rojas-Canales DM, et al. Neurokinin-1 receptor signaling is required for efficient $\mathrm{Ca}^{2+}$ flux in T-Cell-Receptor-Activated T cells. Cell Rep 2020;30:3448-3465.e8.

73. McMahon DB, Carey RM, Kohanski MA, et al. Neuropeptide regulation of secretion and inflammation in human airway gland serous cells. Eur Respir J 2020;55:1901386.

74. Patil MJ, Mekker S, Bautista D, et al. Spingosine-1phosphate activates mouse vagal airway afferent $\mathrm{C}$-fibres via S1PR3 receptors. J Physiol 2019;597:2007-19.

75. Lee LY, Guo Q, Lin AH, et al. Airway hypersensitivity induced by eosinophil granule-derived cationic proteins. Pulm Pharmacol Ther 2019;57:101804.

76. Maher SA, Belvisi MG. Prostanoids and the cough reflex. Lung 2010;188 Suppl 1:S9-12.

77. Grace M, Birrell MA, Dubuis E, et al. Transient receptor potential channels mediate the tussive response to prostaglandin E2 and bradykinin. Thorax 2012;67:891-900.

78. Sutovska M, Adamkov M, Kocmalova M, et al. CRAC ion channels and airway defence reflexes in experimental airway inflammation. Adv Exp Med Biol 2013;756:39-48.

79. Talbot S, Abdulnour RE, Burkett PR, et al. Silencing nociceptor neurons reduces allergic airway inflammation. Neuron 2015;87:341-54.

80. Choudry NB, Fuller RW, Pride NB. Sensitivity of the human cough reflex: effect of inflammatory mediators prostaglandin E2, bradykinin, and histamine. Am Rev Respir Dis 1989;140:137-41.

81. Nichol G, Nix A, Barnes PJ, et al. Prostaglandin F2 alpha enhancement of capsaicin induced cough in man: modulation by beta 2 adrenergic and anticholinergic drugs. Thorax 1990;45:694-8.

82. Lim KG, Rank MA, Kita H, et al. Neuropeptide levels in nasal secretions from patients with and without chronic cough. Ann Allergy Asthma Immunol 2011;107:360-3.

83. Patterson RN, Johnston BT, Ardill JE, et al. Increased tachykinin levels in induced sputum from asthmatic and cough patients with acid reflux. Thorax 2007;62:491-5.

84. Groneberg DA, Niimi A, Dinh QT, et al. Increased expression of vanilloid-1 in airway nerves of chronic cough. Am J Respir Crit Care Med 2004;170:1276-80.

85. Khalid S, Murdoch R, Newlands A, et al. Transient receptor potential vanilloid 1 (TRPV1) antagonism in patients with refractory chronic cough: a double-blind randomized controlled trial. J Allergy Clin Immunol 2014;134:56-62.

86. Belvisi MG, Birrell MA, Wortley MA, et al. XEN-D0501, a novel Transient Receptor Potential Vanilloid 1 antagonist, does not reduce cough in patients with refractory cough. Am J Respir Crit Care Med 2017;196:1255-63.

87. Smith JA, McGarvey LPA, Badri H, et al. Effects of a novel sodium channel blocker, GSK2339345, in patients with refractory chronic cough. Int J Clin Pharmacol Ther 2017;55:712-9.

88. Fahy JV, Wong HH, Geppetti P, et al. Effect of an NK1 receptor antagonist (CP-99,994) on hypertonic salineinduced bronchoconstriction and cough in male asthmatic subjects. Am J Respir Crit Care Med 1995;152:879-84.

89. Burnstock G. Purine and purinergic receptors. Brain Neurosci Adv 2018;2:2398212818817494.

90. Richards D, Gever JR, Ford AP, et al. Action of MK-7264 (gefapixant) at human $\mathrm{P} 2 \mathrm{X} 3$ and $\mathrm{P} 2 \mathrm{X} 2 / 3$ receptors and in vivo efficacy in models of sensitisation. Br J Pharmacol 2019;176:2279-91.

91. Smith JA, Kitt MM, Morice AH, et al. Gefapixant, a P2X3 receptor antagonist, for the treatment of refractory or unexplained chronic cough: a randomised, double-blind, controlled, parallel-group, phase $2 \mathrm{~b}$ trial. Lancet Respir Med 2020;8:775-85.

92. Finger TE, Danilova V, Barrows J, et al. ATP signalling is crucial for communication from taste bust to gustatory nerves. Science 2005;310:1495-9.

93. Garceau D, Chauret N. BLU-5937: A selective P2X3 antagonist with potent anti-tussive effect and no taste alteration. Pulm Pharmacol Ther 2019;56:56-62.

94. Niimi A, Ishihara H, Hida H, et al. Phase 2a randomised, double-blind, placebo-controlled, crossover study of a novel P2X3 receptor antagonist S-600918 in patients with refractory chronic cough. Eur Respir J 2019;54:RCT452.

95. Morice AH, Smith J, McGarvey L, et al. Safety and efficacy of BAY 1817080, a P2X3 receptor antagonist, in patients with refractory chronic cough (RCC). Am J Respir Crit Care Med 2020;201:A7648. 
96. Basoglu OK, Pelleg A, Kharitonov SA, et al. Contrasting effects of ATP and adenosine on capsaicin challenge in asthmatic patients. Pulm Pharmacol Ther 2017;45:13-8.

97. Basoglu OK, Pelleg A, Essilfie-Quaye S, et al. Effects of aerosolized adenosine 5'-triphosphate vs adenosine 5'-monophosphate on dyspnea and airway caliber in healthy nonsmokers and patients with asthma. Chest 2005;128:1905-9.

98. Fowles HE, Rowland T, Wright C, et al. Tussive challenge with ATP and AMP: does it reveal cough hypersensitivity? Eur Respir J 2017;49:1601452.

99. Kamei J, Takahashi Y, Yoshikawa Y, et al. Involvement of $\mathrm{P} 2 \mathrm{X}$ receptor subtypes in ATP-induced enhancement of the cough reflex sensitivity. Eur J Pharmacol 2005;528:158-61.

100. Kollarik M, Undem BJ. Mechanisms of acid-induced activation of airway afferent nerve fibres in guinea-pig. J Physiol 2002;543:591-600.

101. Muroi Y, Ru F, Chou YL, et al. Selective inhibition of vagal afferent nerve pathways regulating cough using Nav 1.7 shRNA silencing in guinea pig nodose ganglia. Am J Physiol Regul Integr Comp Physiol 2013;304:R1017-1023.

102. Brunetti L, Francavilla R, Tesse R, et al. Exhaled breath condensate cytokines and $\mathrm{pH}$ in pediatric asthma and atopic dermatitis. Allergy Asthma Proc 2008;29:461-7.

103. Stephan G, Huang L, Tang Y, et al. The ASIC3/P2X3 cognate receptor is a pain-relevant and ligand-gated cationic channel. Nat Commun 2018;9:1354.

104. Mazzone SB, Tian L, Moe AAK, et al. Transcriptional profiling of individual airway projecting vagal sensory neurons. Mol Neurobiol 2020;57:949-63.

105. Retamal MA, Alcayaga J, Verdugo CA, et al. Opening of pannexin- and connexin-based channels increases the excitability of nodose ganglion sensory neurons. Front Cell Neurosci 2014;8:158.

106. De Ita M, Vargas MH, Carbajal V, et al. ATP releases ATP or other nucleotides from human peripheral blood leukocytes through purinergic P2 receptors. Life Sci 2016;145:85-92.

107. Ohbuchi T, Takenaga F, Hohchi N, et al. Possible contribution of pannexin-1 to ATP release in human upper airway epithelia. Physiol Rep 2014;2:e00227.

108. Bonvini SJ, Birrell MA, Dubuis E, et al. Novel airway smooth muscle-mast cell interaction and a role for the TRPV4-ATP axis in non-atopic asthma. Eur Respir J 2020;56:1901458.

109. Baxter M, Eltom S, Dekkak B, et al. Role of transient receptor potential and pannexin channels in cigarette smoke-triggered ATP release in the lung. Thorax 2014;69:1080-9.

110. Vandenbeuch A, Anderson CB, Kinnamon SC. Mice lacking Pannexin 1 release ATP and respond normally to all taste qualities. Chem Senses 2015;40:461-7.

111. Tordoff MG, Aleman TR, Ellis HT, et al. Normal taste acceptance and preference of PANX1 knockout mice. Chem Senses 2015;40:453-9.

112. Buday T, Kovacikova L, Ruzinak R, et al. TRPV4 antagonist GSK2193874 does not modulate cough response to osmotic stimuli. Respir Physiol Neurobiol 2017;236:1-4.

113. Masuda T, Ozono Y, Mikuriya S, et al. Dorsal horn neurons release extracellular ATP in a VNUT-dependent manner that underlies neuropathic pain. Nat Commun 2016;7:12529.

114. Ma Z, Saung WT, Foskett JK. Action potentials and ion conductances in wild-type and CALHM1-knockout type II taste cells. J Neurophysiol 2017;117:1865-76.

115. Romanov RA, Lasher RS, High B, et al. Chemical synapses without synaptic vesicles: purinergic neurotransmission through a CALHM1 channel-mitochondrial signalling complex. Sci Signal 2018;11:eaao1815.

116. Ma Z, Taruno A, Ohmoto M, et al. CALHM3 is essential for rapid ion channel-mediated purinergic neurotransmission of GPCR-mediated tastes. Neuron 2018;98:547-561.e10.

117.Ji RR, Nackley A, Huh Y, et al. Neuroinflammation and central sensitisation in chronic and widespread pain. Anesthesiology 2018;129:343-66.

118.Bonham AC, Skizawa SI, Joad JP. Plasticity of central mechanisms of cough. Pulm Pharmacol Ther 2004;17:453-7.

119. Mastitskaya S, Turovsky E, Marina N, et al. Astrocytes modulate baroreflex sensitivity at the level of the nucleus of the solitary tract. J Neurosci 2020;40:3052-62.

120. Accorsi-Mendonça D, Bonagamba LGH, Machado $\mathrm{BH}$. Astrocytic modulation of glutamatergic synaptic transmission is reduced in NTS of rats submitted to shortterm sustained hypoxia. J Neurophysiol 2019;121:1822-30.

121. Matott MP, Kline DD, Hasser EM. Glial EAAT2 regulation of extracellular nTS glutamate critically controls neuronal activity and cardiorespiratory reflexes. J Physiol 2017;595:6045-63.

122. Driessen AK, McGovern AE, Narula M, et al. Central mechanisms of airway sensation and cough hypersensitivity. Pulm Pharmacol Ther 2017;47:9-15. 123. Ternesten-Hasséus E, Larsson C, Larsson S, et al. 
Capsaicin sensitivity in patients with chronic cough-results from a cross-sectional study. Cough 2013;9:5.

124. Martucci KT, Ng P, Mackey S. Neuroimaging chronic pain: what have we learned and where are we going? Future Neurol 2014;9:615-26.

125. Napadow V, Sclocco R, Henderson LA. Brainstem neuroimaging of nociception and pain circuitries. Pain Rep 2019;4:e745.

126. Cho PSP, Fletcher HV, Turner RD, et al. Impaired cough suppression in chronic refractory cough. Eur Respir J 2019;53:1802203.

127. Ando A, Mazzone SB, Farrell MJ. Altered neural activity in brain cough suppression networks in cigarette smokers. Eur Respir J 2019;54:1900362.

128. Gibson PG, Vertigan AE. Speech pathology for chronic cough: a new approach. Pulm Pharmacol Ther 2009;22:159-62.

Cite this article as: Singh $\mathrm{N}$, Driessen $\mathrm{AK}, \mathrm{McGovern}$ AE, Moe AAK, Farrell MJ, Mazzone SB. Peripheral and central mechanisms of cough hypersensitivity. J Thorac Dis 2020;12(9):5179-5193. doi: 10.21037/jtd-2020-icc-007
129. Chamberlain S, Birring SS, Garrod R.

Nonpharmacological interventions for refractory chronic cough patients: systematic review. Lung 2014;192:75-85.

130. Mainero C, Boshyan J, Hadjikhani N. Altered functional MRI resting-state connectivity in periaquductal gray networks in migraine. Ann Neurol 2011;70:838-45.

131. Matsuo Y, Kurata J, Sekiguchi M, et al. Attenuation of cortical activity triggering descending pain inhibition in chronic low back pain patients: a functional magnetic resonance imaging study. J Anesth 2017;31:523-30.

132. Berna C, Leknes S, Ahmad AH, et al. Opioid-independent and opioid-mediated modes of pain modulation. J Neurosci 2018;38:9047-58.

133. Smith J, Allman D, Badri H, et al. The Neurokinin-1 receptor antagonist Orvepitant is a novel antitussive therapy for chronic refractory cough: results from a Phase 2 pilot study (VOLCANO-1). Chest 2020;157:111-8. 